eventually by falling into general disrepute and perhaps being ignored totally. It is unenforceable because you would not be able to assess the mountain of forms that would descend upon you, and you would have grave difficulties in drawing a legal line between micro- and "macroorganisms". To enforce it rigidly would also require you to halt many quite "normal" human activities-for example the examination or treatment of people with $\mathrm{X}$-rays (surely likely to alter the genetic constitution of microorganisms to which we are hosts), and the treatment of crops with chemicals (which even if they do not alter the genetic constitution of individual microorganisms will surely alter the constitution of populations of microorganisms). Finally, it makes a nonsense of the evolutionary process: populations of all microorganisms are continuously changing their genetic constitutions and have been doing so since, quite literally, the origin of life. I fear that no law will stop this vast activity.

It is just not good enough to expect scientists to identify techniques (and organisms?) which may be excluded from regulation because they do not present "any potential hazard". Not only is the range of organisms studied so wide, it is impossible to prove that any human activity is completely safe under any circumstances. Dangerous activities, on the other hand, can usually be positively identified. Whether you list activities to be excluded from the regulations or just those to be included, the regulations will have to be continuously amended to take the results of research into account.

It would be far more effective to draft the regulations to include only those techniques of known danger or which scientists judge to be of potential danger, and actively to involve both the scientific community and others in both the assessment of these dangers and the administration of the law itself. Yours sincerely,

Michael Ashburner

\title{
An open reply from the Director of the Executive
}

John Locke, Director of the Health and Safety Executive, takes up the points in Michael Ashburner's letter

Dear Dr Ashburner,

I am glad to have this opportunity of commenting on the points raised by you.

The Government and the Health and Safety Commission have both accepted what you call the "moderate" view that the recommendations of the Williams Report are reasonable. This means that the carrying out of the techniques described in shorthand as "genetic engineering" should be permitted where they offer prospects of social benefit, provided that adequate steps are taken to protect workers in the laboratories and people outside those laboratories from harm. The Williams Committee recommended that in order to achieve this protection those using these techniques, whether in official laboratories or in universities or in industrial firms, should be required to notify their intentions and to seek the advice of the Advisory Group which is being set up by the Government.

The proposals for Regulations, circulated for comment by the Health and Safety Commission, are intended to cstablish this requirement to notify. The Commission does not believe that it would be right in a matter of this importance to leave people free to decide whether to abide by the recommendations of the Williams Committee. They believe that everybody should be placed in the same position of being required to give this notification.

The draft Regulations provide for notification to the Health and Safety Executive because we are a statutory body whereas the Advisory Group will have no statutory status. But I really must protest at the suggestion that the Advisory Group would play a subservient role to the Health and Safety Executive. This is simply not the case. It will be for the Advisory Group to lay down the conditions which need to be observed to enable the experiments to proceed safely. Our aim will be to make sure that the Advisory Group is in fact consulted, and secondly to make sure that its recommendations are followed. Both steps are necessary if workers and the general public are to be adequately protected and this is a responsibility placed upon us by Parliament.

Nothing in the Regulations therefore will remove the Advisory Group from its central role in the dialogue between those who wish to carry out experimentation of this kind and those who are competent to advise on the nature of the precautions which need to be taken.

The main point which you raise is that the proposed Regulations are drawn too widely and would catch many activities which do not present special hazards and which were not dealt with by the Williams Committee. This is certainly true. But the Williams Committee clearly found it very difficult to produce a precise description of the kind of work which they wanted reported. And it is no good at all saying that scientists shall notify their intention of carrying out certain types of work unless they are told pretty precisely what is to be covered.

We hope that as a result of comments on the proposed Regulations, we may be able to suggest a definition of what is to be notified, which, as you say, will cover all those types of work which could present special hazards and require special controls, and which will not be exposed to some of the kinds of objections raised in your note. I entirely agree that neither we nor the Advisory Group should be subjected to "mountains of forms". On the other hand, I am sure you would agree that we must not devise a definition of what is to he notified which would leave out certain types of work which might prove to present special hazards. It seems to us we must err, if we err at all, on the side of having rather more than we want notified rather than too little.

I hope therefore that all those concerned in this field will help us with devising a definition of the activities to be notified to the Advisory Group and to my Executive which will be sensible, workable, and capable of offering the protection to which workers and the general public are entitled.

Yours faithfully, J. H. Locke 